\title{
CARRIER ROBOT FOR THE TRANSPORTATION OF MATERIALS IN STEEP MOUNTAINS
}

\author{
Akio Terai, Department Chief of Research \& Development Center, \\ Komatsu Zenoah Co., 2-142-1 Sakuragaoka \\ Higashi-Yamato-shi Tokyo 189, Japan \\ Kazumi Uchida, Section Manager of Technical Research Center \\ The Kansai Electric Power Co. \\ 11-20 Nakoji 3-chome, Amagasaki-shi \\ Hyogo Pref. 661, Japan \\ Richard Montgomery, Service Manager \\ Komatsu Zenoah America, Inc. \\ 1505 Pavilion Place Suite \\ A Norcross, GA 30093, U.S.A.
}

\begin{abstract}
With $67 \%$ of Japan's total land mass covered by forests, $70 \%$ of which comprise steep forest slopes of more than 15 degrees (see Fig. 1), the transportation of materials to and from mountain areas is a subject of vital importance. The needs for such transportation range from the supply of living essentials to the support for forestry activities, the construction of power cable towers (including inspection and maintenance), forestry service, to many others. These days, however, finding sufficient manpower for transportation in forested areas is becoming ever more difficult, and this has given rise to the search for a suitable alternative. The topic I will speak on, "a robot for transporting materials in mountain areas," addresses this need, and today I will explain the robot's background, features, functions and structures. Furthermore, I will refer to various salient points we have noted during research and development of our "field robot for mountain areas."

Fig. 1 Constitution of Japan's Land Mass

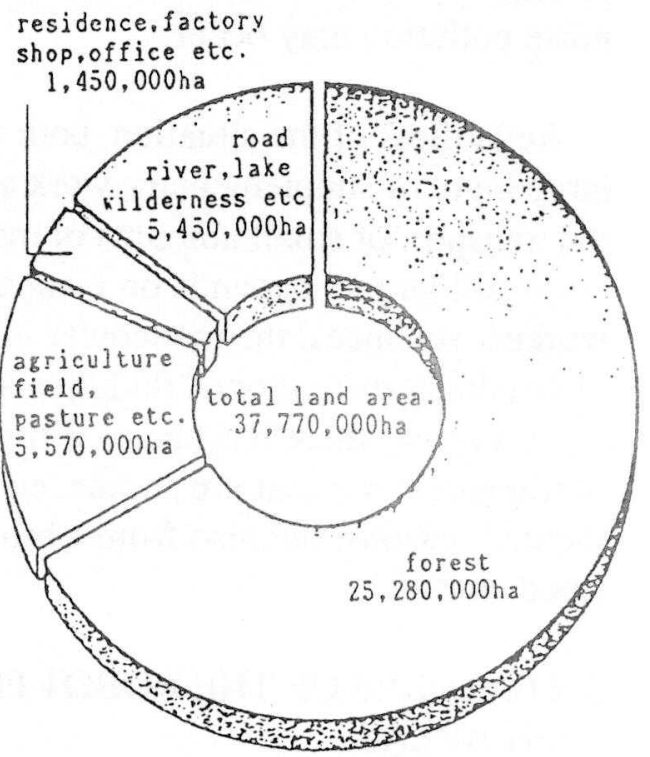




\section{INTRODUCTION}

Provided there is adequate demand for goods and materials, conventional methods of transportation in mountains can be generally classified as follows:

(1) Temporary roads are constructed for use by conventional vehicles.

(This method is mainly applied to flat or moderately sloped areas.)

The structure and width of the road depends on the kind of construction machinery used and the kind of conventional transport vehicle. Regardless, a temporary construction is required.

(2) A temporary cable way is constructed for use with a transporter.

(This method is mainly applied to steep sloped areas.)

The method is often employed when a slope exceeds the climbing abilities of conventional transport vehicles. The structure depends on the scale of transportation and the geographic conditions. Trees obstructing the construction of the ropeway, and the overall operation for that matter, must be cut down. This kind of situation can often provoke animosity from the landowners.

(3) A temporary heliport is constructed for use by a transport helicopter.

(This method mainly applies to steep rocky mountain areas.)

Costwise, this method compares favorably with the ropeway. Moreover, it is advantageous from the point of easy construction, working conditions and environmental preservation, factors that make it popular for certain applications. On the other hand, it demands regular heliport maintenance, and the influence of weather conditions can result in operational problems. Also, in areas where there are houses, the problem of noise pollution may occur.

Regardless of the situation, both of the above methods tend to require relatively large input of supplementary work and expense, so in many cases are not suitable for the transport of small amounts of materials. This is why transportation in mountainous areas still largely depends on manpower. But as the average age of specialized forest workers advances, the manpower in mountain areas is steadily decreasing, making it increasingly difficulty of finding adequate manpower.

As a result, there has been a growing demand for the development of new methods of transportation that are simple, economical and labor saving, not only for direct commercial reasons, but also from a broader point of view of overall forest protection and flood control.

\section{FEATURES OF THE ROBOT FOR TRANSPORTING MATERIALS IN MOUN- TAIN AREAS}

The features of the robot are summarized as follows (see Fig. 2, 3), with main specifications shown in Table 1.

(1) Two-system traveling, by crawler and by monorail. 
(2) Automatic transition between crawler traveling and monorail traveling.

(3) Control by either of two control systems-unmanned-control traveling or remote-control traveling.

(4) A single robotic vehicle is able to transport materials from the foot of the mountain to the mountain top.

(5) Carry load of materials is 10 times that of single loads carried by manpower.

Fig. 2 Transport robot's operation system

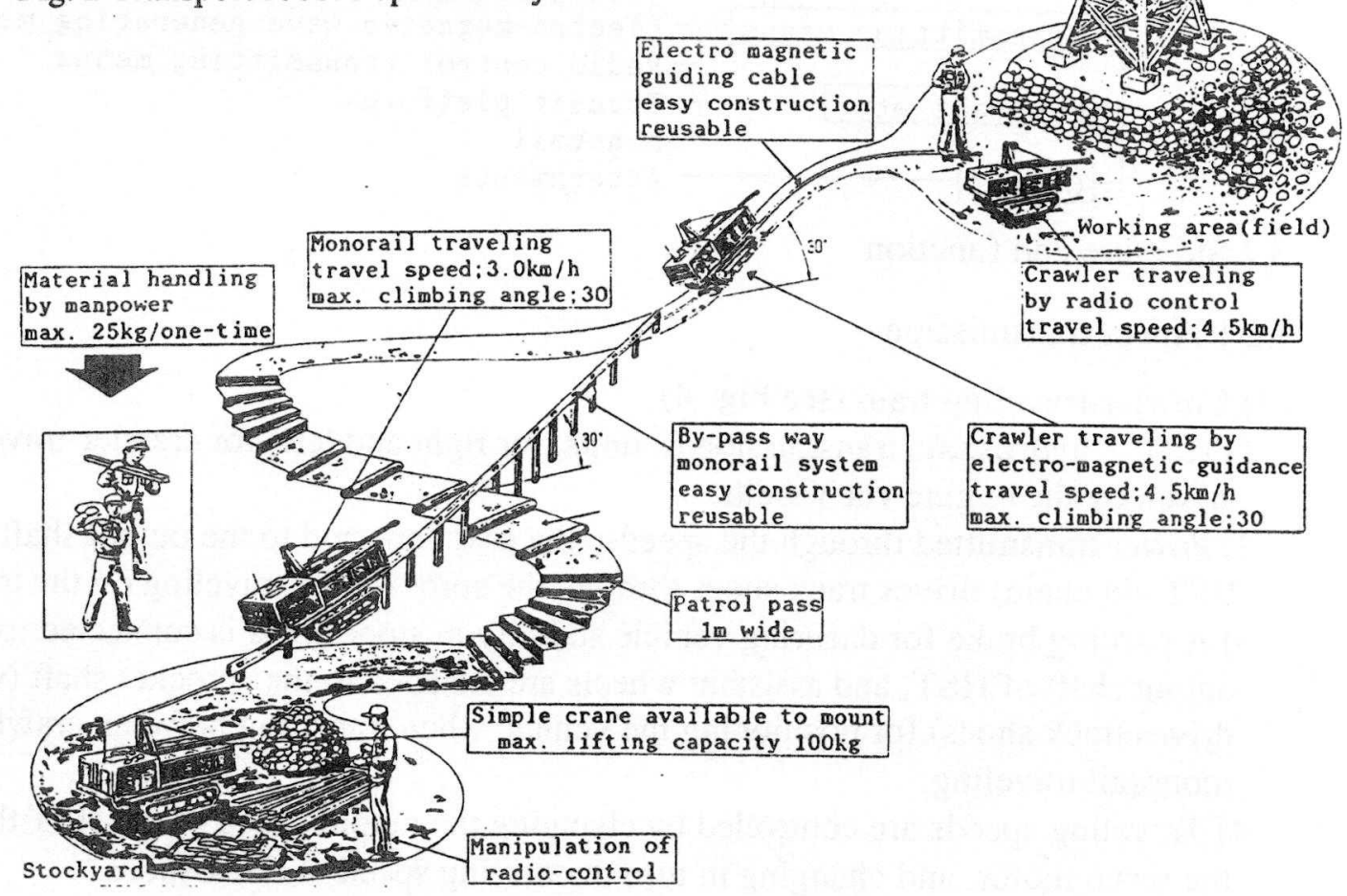

Fig. 3 Example of transport robot operation

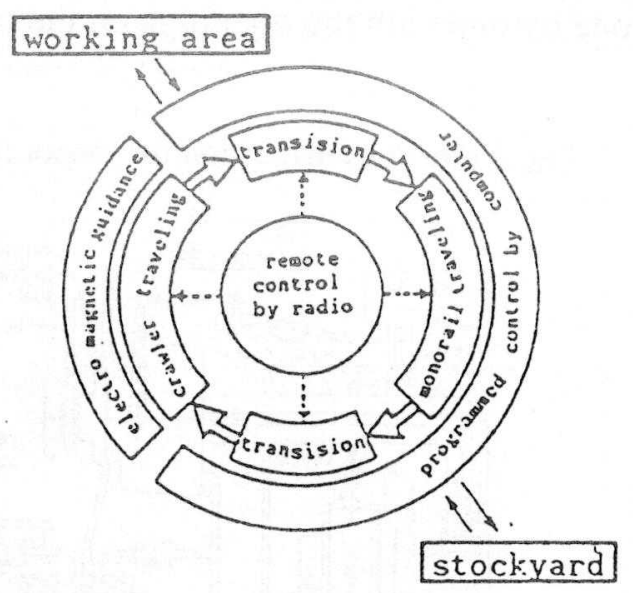

Table 1 Main Specifications

\begin{tabular}{|c|c|c|c|}
\hline & ITEM & \multicolumn{2}{|c|}{ SPECIFICATIONS } \\
\hline \multicolumn{2}{|c|}{ weight of vehicle, dry } & \multicolumn{2}{|l|}{$560 \mathrm{~kg}$} \\
\hline \multicolumn{2}{|c|}{$\max$. loading weight } & \multicolumn{2}{|l|}{$300 \mathrm{~kg}$} \\
\hline \multicolumn{2}{|c|}{ output of engine } & \multicolumn{2}{|c|}{$11 \mathrm{ps} / 3000 \mathrm{rpm}$} \\
\hline \multicolumn{2}{|c|}{ dimension $(L \times W \times H)$} & \multicolumn{2}{|c|}{$2,270 \times 950 \times 950 \mathrm{~mm}$} \\
\hline \multirow{4}{*}{ 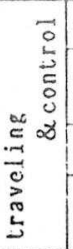 } & slockyard\&workingarea & crawler & radio-control \\
\hline & $\begin{array}{l}\text { existing road bith } \\
\text { gentle slofe }\end{array}$ & crawler & $\begin{array}{l}\text { electromagnetic } \\
\text { guidance }\end{array}$ \\
\hline & hedge, river, stairs etc & mono-rail & progran \\
\hline & $\begin{array}{l}\text { existing road with } \\
\text { steep slope }\end{array}$ & mono-rajl & progran \\
\hline \multicolumn{2}{|c|}{$\begin{array}{l}\text { effective distance of radio } \\
\text { control-wave }\end{array}$} & \multicolumn{2}{|l|}{$\max \cdot 100 \mathrm{n}$} \\
\hline
\end{tabular}




\section{PRINCIPAL STRUCTURE AND FUNCTIONS}

\subsection{Constitution}

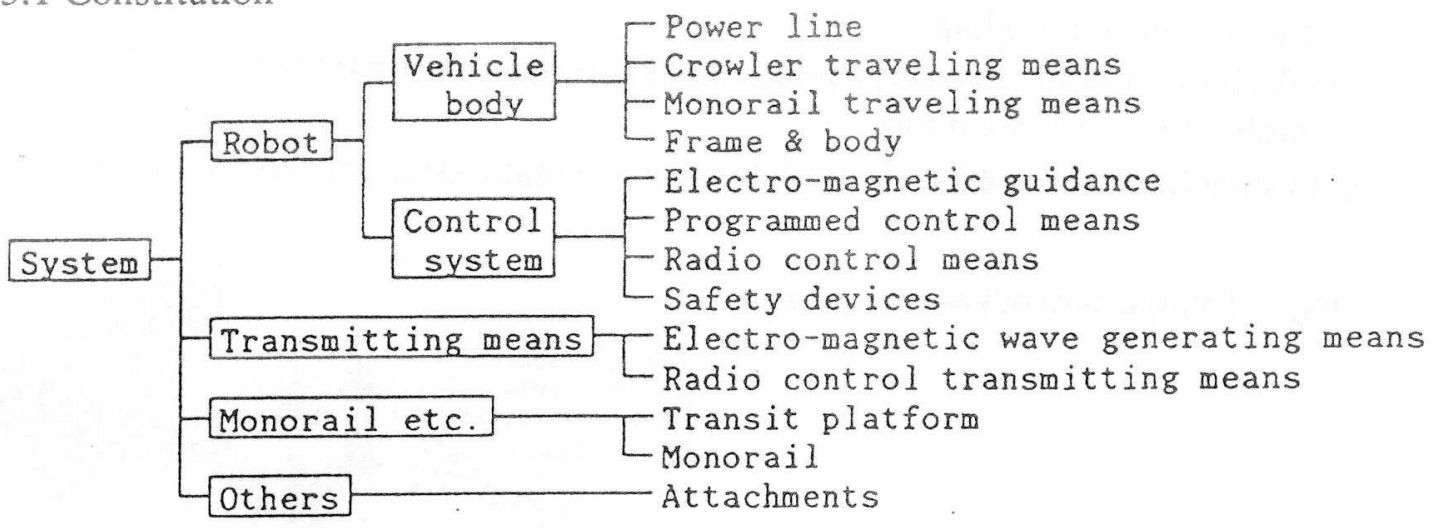

3.2 Structure and function

\subsubsection{Power transmission}

(1) Crawler-traveling train (see Fig. 4)

1) HST -- hydrostatic transmission (2 units, for right and left) for crawler-traveling, driven by the engine via V-belts.

2) Power transmitted through the speed-reducer (connected to the output shaft of HST via chain) drives track shoes through the sprocket for traveling on the trail

3) A parking brake for ensuring vehicle stability in slope areas is connected to the output shaft of HST, and assistant wheels are attached to the sprocket shaft (which drives track shoes) for positioning the vehicle when transiting between crawler and monorail traveling.

4) Traveling speeds are controlled by changing the output speed of the HST through the servo motor, and changing in turn the driving speed of track shoes.

(2) Monorail traveling train (see Fig. 5)

1) Variable pump for monorail traveling is driven by the engine via a V-belt.

2) The fixed motor is driven by hydraulic pressure from the variable pump. Power from the output shaft drives the monorail sprocket shaft, and teeth in the outer periphery of the sprocket engage one by one with the openings on the rail, to move the vehicle.

Fig. 4 Power transmission for crawler travel

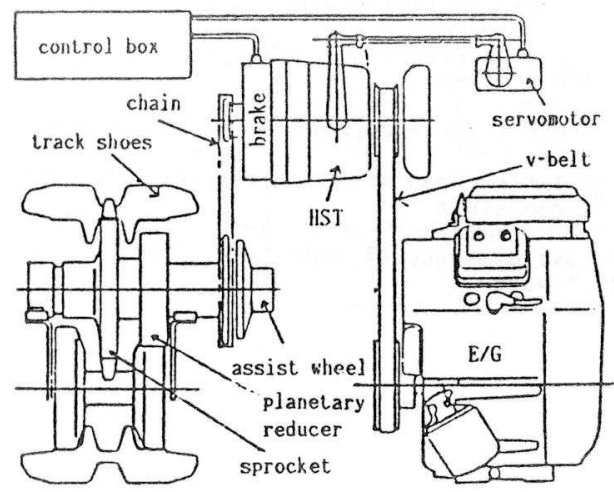

Fig. 5 Power transmission for monorail travel

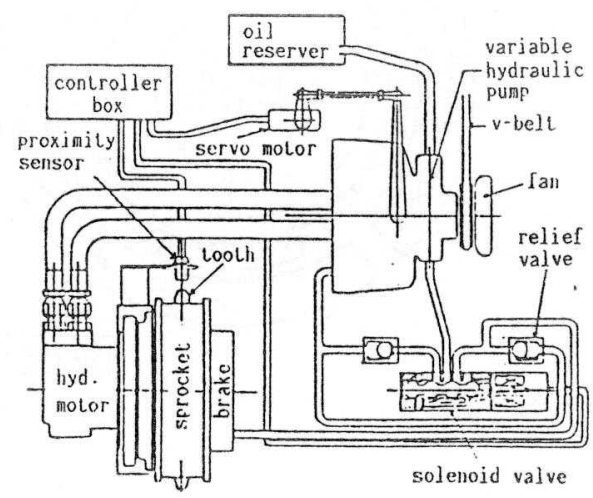


3) The brake mounted on the output shaft of the motor performs the functions of holding the vehicle stable in sloped areas and provides emergency braking should the vehicle go out of control.

4) Traveling speed is controlled by changing the output shaft speed of the motor, with the delivery of the variable pump changed by the servo motor.

\subsubsection{Automatic transition}

Automatic transition between crawler traveling and monorail traveling uses the transit platform (see Fig.6, 7). The robot is able to achieve automatic transition by following a four-step procedure actuated by the signal dogs on the platform, which allows it to enter the platform. Next, we will explain the function and structure of the transition from crawler traveling to monorail traveling.

Fig. 6 Structure of transit platform

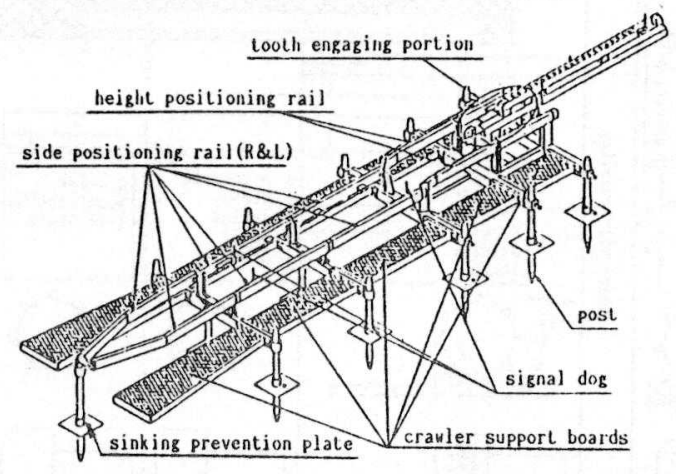

Fig. 7 Relation between transit platform and vehicle

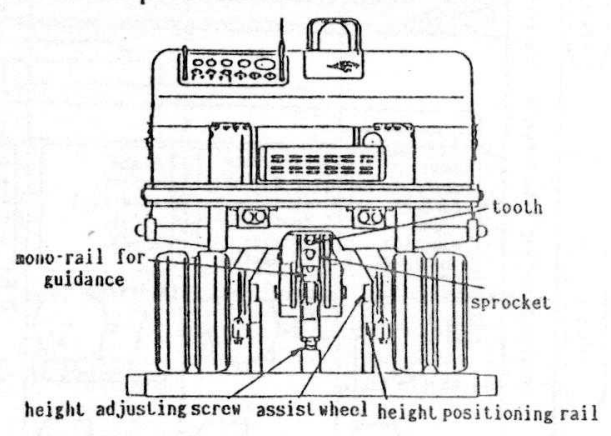

(1) Structure of the transit platform

1) The platform is comprised of support boards, rails for setting the position (left or right), rails for setting the height, the engaging portion of the monorail sprocket teeth (hereafter called the teeth) and eight signal-dogs.

2) When the assistant wheels of the vehicle touch the rail for setting the position, engagement of the teeth is automatically activated.

3) The platform divided into units can be built up with bolts. Each of the units weighs less than $25 \mathrm{~kg}$, for easy carrying by a person.

4) Steel tube posts are inserted into the ground and fixed in place. In soft ground, sinking-prevention plates are attached to the posts. When removed, disassemble the platform by removing the bolts after pulling out or cutting off the posts.

(2) Procedure for automatic transition (see Fig. 8)

Four steps on the platform:

1) The robot decreases the crawler speed at the first signal, and places the one of the teeth directly below, to enter the platform.

2) The robot receives the second signal just before entering the height-setting-rail and confirms tooth position while advancing along the rail with the assistant wheel.

3) As the robot advances along the rail with the assistant wheels, the tooth posi- 
tioned directly underneath strikes the monorail and turns the sprocket. This turning causes the tooth to engage one of the openings in the rail. Then, at the third signal, the assistant wheels and sprockets are activated.

4) At the fourth signal, which is actuated just before the assistant wheels leave the rail, the crawlers and assistant wheels stop. The sprockets are then accelerated and the transition is complete.

Fig. 8 Automatic transition between crawler and monorail travel
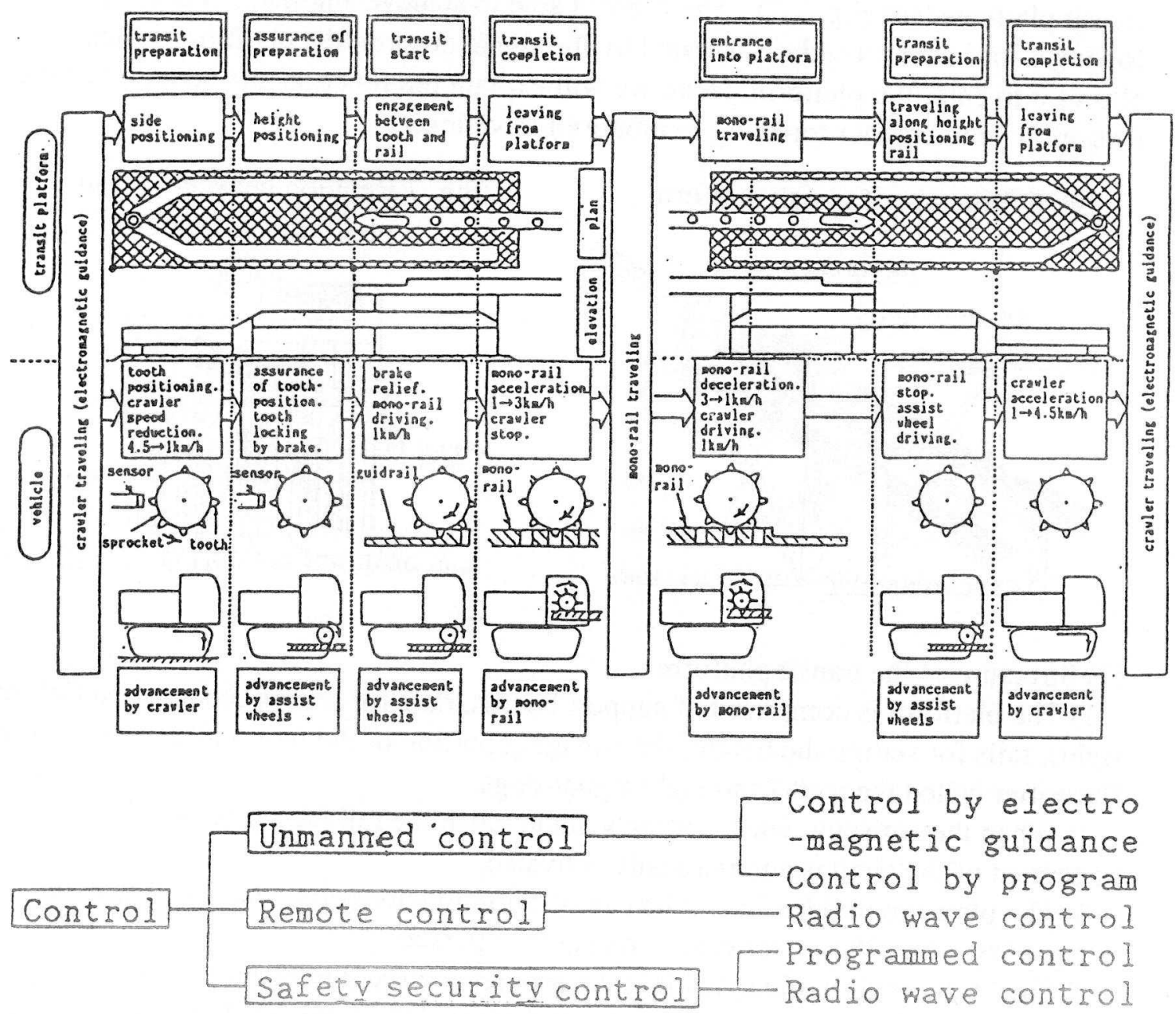

Control of the transport robot is classified as shown at left. Figures 9,10 and 11 show the outline of the system and the flow of signals. The remote control overrides the unmanned control, and engine start/stop, emergency stop of the unmanned control.

\section{(1) Electromagnetic guidance}

Six pick-up coils (sensors) mounted in the robot sense the magnetic line of force transmitted from the guide wire, which is laid on the ground. The vehicle is steered by controlling the crawler speeds on the left and right sides in response to the sensed strength and frequencies, and this enables automatically guided traveling and switchback traveling. In addition, the best traveling speed is automatically selected to match 
the slope of the road, using a separately equipped angular sensor to enhance the guiding performance.

(2) Programmed control

According to a preset program, the computer commands automatic transition and monorail traveling by actuating the signal dogs on the platform. It also controls speed selection by matching the inclination of the rail, as for electromagnetic guidance.

(3) Remote control

With a radio transmitter control on $280 \mathrm{MHz}$ waveband, the robot movements can be controlled.

Fig. 9 Block Diagram of system

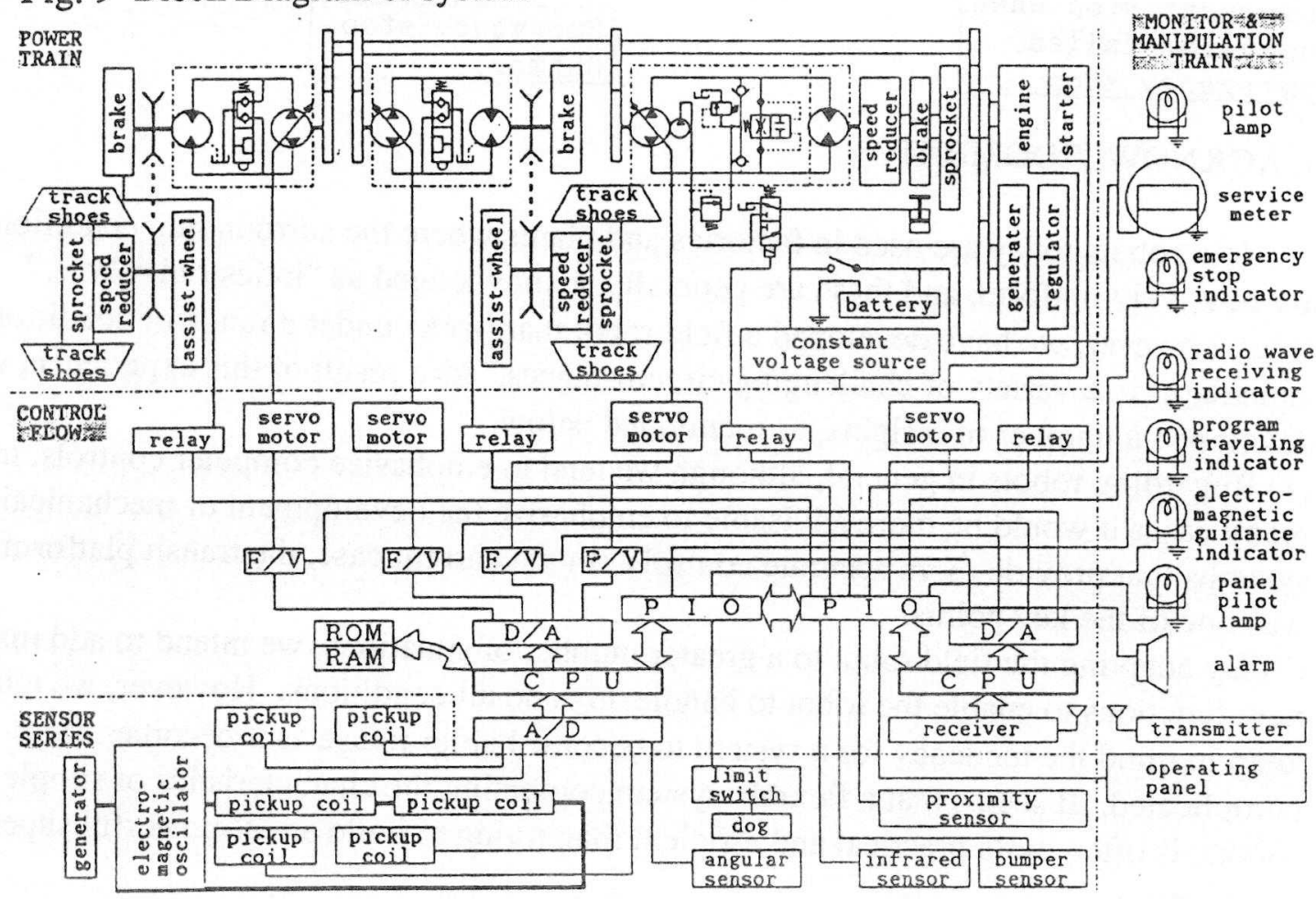

Fig. 10 Outline of signal transmission in unmanned control

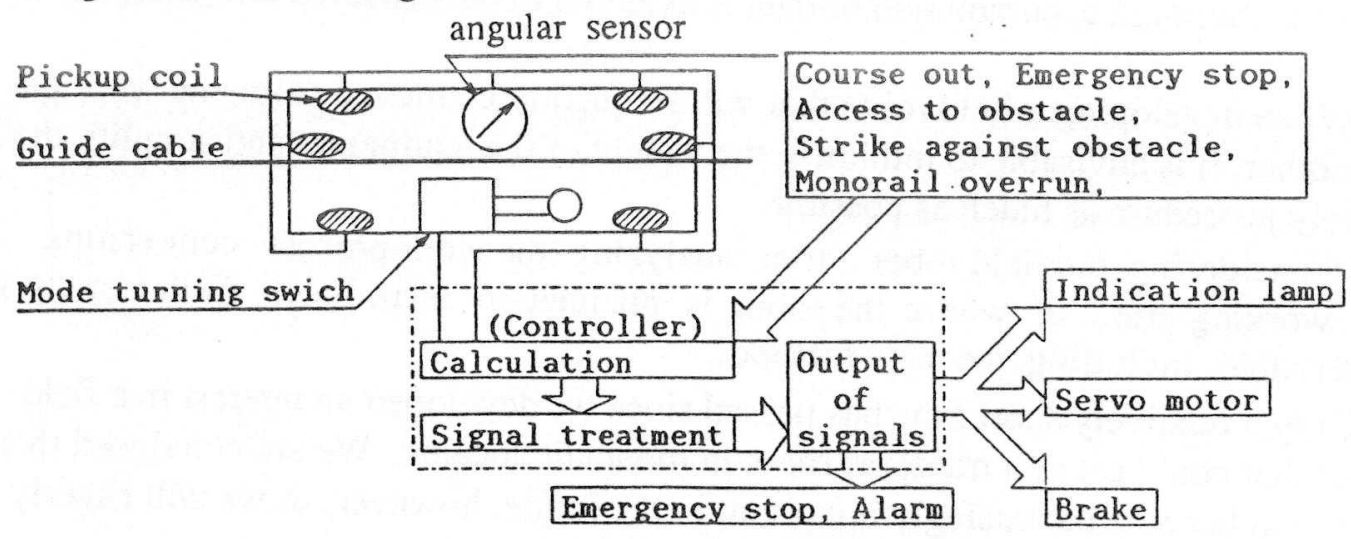


Fig. 11 Outline of signal transmission in remote control

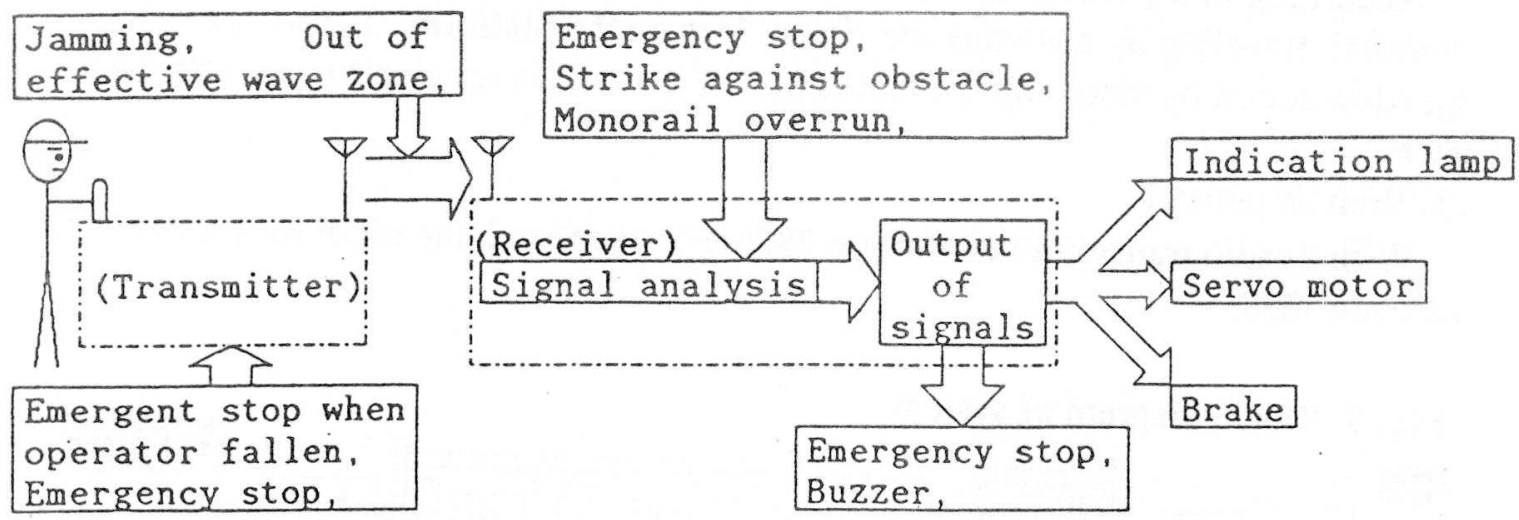

\section{ACKNOWLEDGMENT}

Most robots today are used in factories and plants where the surrounding conditions are relatively uniform, and these are generally acknowledged as "industrial robots." Now, however, we have developed a field robot that works under a range of conditions and adapts to a variety of challenging circumstances. As a result of this experience, we developed a number of insights, as mentioned below.

(1) Regarding robots in general, although we tend to emphasize computer controls, in many cases it would be more advisable to emphasize the development of mechanical systems that provide more accurate controls. In the current case, the transit platform was one of the key points.

(2) By adapting the field robot to a greater number of situations, we intend to add many new functions to enable the robot to handle any and all conditions. However, we must keep in mind the tendency for a system to become harder to use as it becomes more complicated. It seems that a flexible system combining the characteristics of simple robots, is often more practical and efficient than trying to build an all-powerful supermachine.

(3) When designing the transport course necessary for introducing the robot to a working area, thorough accumulation of data is essential to the effective utilization of robots.

(4) When developing a field robot that will frequently be moved from one work place to another, it is advisable to minimize the weight of the equipment and simplify the assembly procedure as much as possible.

(5) Considering the field robot, after analyzing the work process concerning the working site, in where the robot is planned to introduce, further study is desirrable including the new method.

Only a relatively short time has passed since we developed an interest in a field robot that could act as a transport robot in mountain locales. We are convinced this field will become increasingly important in the future, however, so we will eagerly continue our research and development. 